\title{
Imatinib and GNF-5 Exhibit an Inhibitory Effect on Growth of Hepatocellar Carcinoma Cells by Downregulating S-phase Kinase-associated Protein 2
}

\author{
Haibo Zhang ${ }^{1 / *}$, Junkoo $\mathrm{Yi}^{2}{ }^{2 *}$, Duhak Yoon', Zaeyoung Ryoo ${ }^{3}$, Inkyu Lee ${ }^{4}$, Myoungok Kim ${ }^{1}$ \\ ${ }^{1}$ Department of Animal Science and Biotechnology, Kyungpook National University, Sangju, ${ }^{2}$ Gyeongsangbukdo Livestock \\ Institute Research, Yeongju, ${ }^{3}$ School of Life Science, Kyungpook National University, ${ }^{4}$ Departments of Internal Medicine, \\ Biochemistry and Cell Biology, Kyungpook National University School of Medicine, Daegu, Korea
}

\begin{abstract}
Hepatocellular carcinoma (HCC) is the most common primary liver cancer and is one of the leading causes of cancer-related deaths worldwide. Imatinib and GNF-5 are breakpoint cluster region-Abelson murine leukemia tyrosine kinase inhibitors which have been approved for the treatment of chronic myeloid leukemia and various solid tumors. However, the effect and underlying mechanisms of imatinib and GNF-5 in HCC remain poorly defined. In this study, we investigated the anticancer activity and underlying mechanisms of imatinib and GNF-5 in HepG2 human hepatocarcinoma cells. Cell proliferation and anchorage-independent colony formation assays were done to evaluate the effects of imatinib and GNF-5 on the growth of HepG2 cells. The cell cycle was assessed by flow cytometry and verified by immunoblot analysis. Gene overexpression and knockdown assays were conducted to evaluate the function of S-phase kinase-associated protein 2 (Skp2). Imatinib and GNF-5 significantly inhibited the growth of HepG2 cells. Imatinib and GNF-5 induced G0/G1 phase cell cycle arrest by downregulating Skp2 and upregulating p27 and p21. Overexpression of Skp2 reduced the effect of imatinib and GNF-5 on HepG2 cells. Knockdown of Skp2 suppressed the proliferation and induced G0/ G1 phase arrest. Furthermore, knockdown of Skp2 enhanced the effect of imatinib and GNF-5 on growth of HepG2 cells. In conclusion, imatinib and GNF-5 effectively suppress HepG2 cell growth by inhibiting Skp2 expression. Skp2 promotes the cell proliferation and reverse G0/G1 phase cell cycle arrest and it represents a potential therapeutic target for HCC treatment.
\end{abstract}

Key Words Hepatocellular carcinoma, Cell cycle, S-phase kinase-associated protein 2, Imatinib, GNF-5

\section{INTRODUCTION}

Hepatocellular carcinoma (HCC) is the fourth most common cause of cancer-related death worldwide [1]. Almost $85 \%$ of HCC cases occur in low and middle income countries, especially in Asia and Africa [2]. Early stage HCC can be treated effectively by local ablation, surgical resection, or liver transplantation [3]. However, most HCC patients are diagnosed at an advanced stage. Food and Drug Administration in the United States approved Sorafenib as the first-line agent for advanced HCC; however, its efficacy is limited [4].

S-phase kinase-associated protein 2 (Skp2) is a member of the F-box family proteins. It functions as a promoter of cell cycle progression by stimulating ( ) the ubiquitination and subsequent degradation of cell cycle inhibitors, including p21, p27, p57, and cyclin E $[5,6]$. High expression of Skp2 has been observed in various human cancers and is associated with poor prognosis and adverse therapeutic outcomes, suggesting that Skp2 functions as an oncogene [7,8]. Inhibition of Skp2 expression has been shown to exhibit a potent anti-proliferative effect in various cancer models [9-11].

Imatinib (Gleevec, Glivec) is a synthetic tyrosine kinase inhibitor of the breakpoint cluster region-Abelson murine leukemia (Bcr-Abl) fusion gene and is used in the treatment of chronic myeloid leukemia (CML) [12]. Imatinib has also been used to treat gastrointestinal stromal tumors and various other malignancies [13-15]. GNF-5 is a selective, non-ATP-competitive inhibitor of Bcr-Abl and is used in combination with an ATP-competitive inhibitor, such as imatinib or nilotinib, to enhance antitumor effects in vitro [16]. In particular, Skp2 acts

Received August 28, 2020, Revised November 18, 2020, Accepted November 21, 2020

Correspondence to Myoungok Kim, E-mail: ok4325@knu.ac.kr, https://orcid.org/0000-0001-6650-7734

Check for updates

*These authors contributed equally to this work as co-first authors.

(i) (\$) This is an Open Access article distributed under the terms of the Creative Commons Attribution Non-Commercial License, which permits unrestricted noncommercial use, distribution, and reproduction in any medium, provided the original work is properly cited.

Copyright $\odot 2020$ Korean Society of Cancer Prevention 
as a downstream factor of Bcr-Abl to promote the cell cycle transition in CML. Targeting the Skp2/Bcr-Abl pathway effectively suppresses CML growth $[17,18]$.

In the present study, we examined the effects of imatinib and GNF-5 on the growth of HCC cells. Furthermore, we evaluated the function of Skp2 on the activities of imatinib and GNF-5 by utilizing Skp2 overexpressing and knockdown HepG2 cells.

\section{MATERIALS AND METHODS}

\section{Cell culture and reagents}

The HepG2 human hepatocarcinoma and 293T cell lines were purchased from the ATCC (Manassas, VI, USA) and maintained in Dulbecco's modified Eagle's medium containing $10 \%$ FBS and $1 \%$ penicillin/streptomycin. Cells were maintained at $37^{\circ} \mathrm{C}$ with $5 \% \mathrm{CO}_{2}$ in a humidified incubator. Imatinib and GNF-5 were purchased from Cayman Chemical (Ann Arbor, MI, USA).

\section{Cell viability assay}

Cell viability was measured by the Cell Counting Kit-8 (Dojindo Laboratories, Kumamoto, Japan). Briefly, cells were seeded into 96-well plates $\left(2 \times 10^{3}\right.$ cells/well). After 24 hours, 20 $\mu \mathrm{M}$ of imatinib or GNF-5 was added, followed by $0,24,48$, or 72 hours of incubation. Ten $\mu \mathrm{L}$ of Cell Counting Kit- 8 solution was then added to each well, and the mixture was incubated for additional 2 hours at $37^{\circ} \mathrm{C}$. The absorbance of each well at $450 \mathrm{~nm}$ was measured using a microplate spectrophotometer (BMG Labtech, Ortenberg, Germany).

\section{Anchorage-independent colony formation assay} HepG2 cells $\left(8 \times 10^{3}\right.$ cells/well $)$ suspended in Dulbecco's modified Eagle's medium with $10 \%$ FBS were added to $0.3 \%$ agar in a top layer over a base layer of $0.6 \%$ agar with the indicated concentrations of imatinib and GNF-5. The cultures were incubated at $37^{\circ} \mathrm{C}$ in a $5 \% \mathrm{CO}_{2}$ incubator for two weeks and colonies were counted under a light microscope.<smiles>Cc1ccc(NC(=O)c2ccc3c(c2)CC2CN(C)CCN2C3)cc1Nc1nccc(-c2cccnc2)n1</smiles>

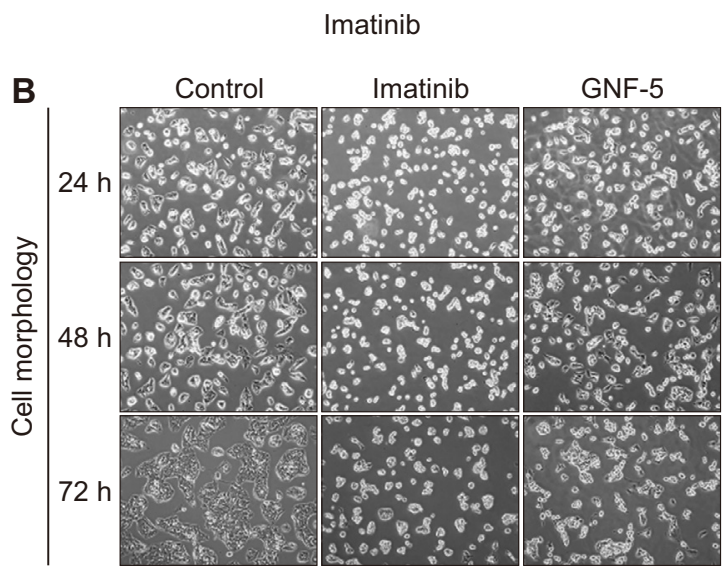

D

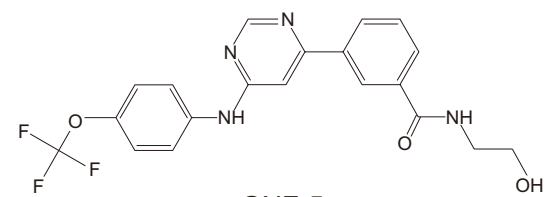

GNF-5

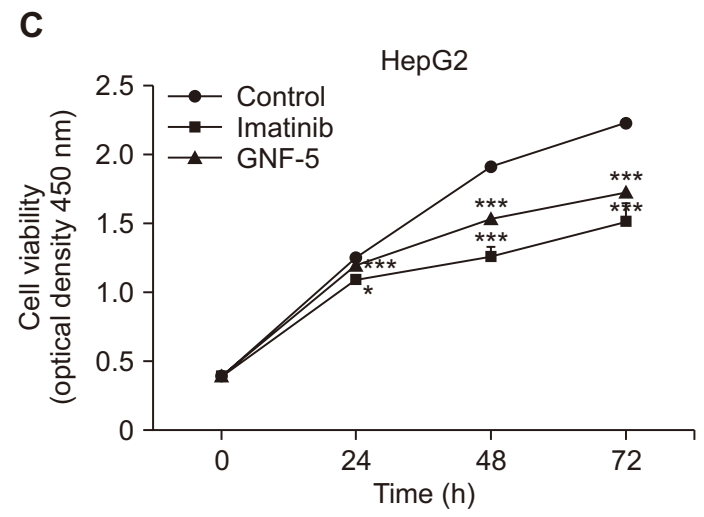

HepG2

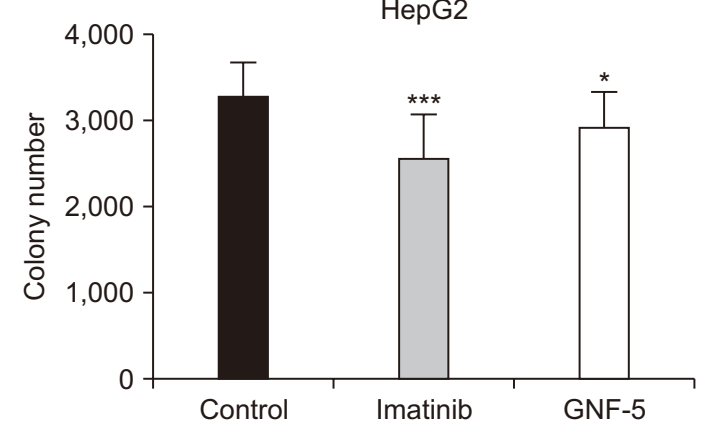

Figure 1. Imatinib and GNF-5 inhibit the growth of HepG2 cells. (A) Chemical structures of imatinib and GNF-5. (B) Cell morphology was examined under an inverted light microscope $(\times 100)$. (C) Viability of HepG2 cells was measured using the Cell Counting Kit-8 assay. (D) Effects of imatinib and GNF-5 on anchorage-independent growth of HepG2 cells $(\times 50) .{ }^{*} P<0.05 ;{ }^{* *} P<0.01 ;{ }^{* *} P<0.001$. 


\section{Cell cycle analysis by flow cytometry}

The cells were seeded into 6-well plates and treated with or without imatinib $(20 \mu \mathrm{M})$ or GNF-5 $(20 \mu \mathrm{M})$ for 24 hours, harvested, and fixed in $70 \%$ ice-cold $\mathrm{EtOH}$ at $-20^{\circ} \mathrm{C}$ overnight. On the following day, the collected cells were washed twice with PBS, treated with $100 \mu \mathrm{g} / \mathrm{mL}$ RNase A for 20 minutes, and propidium iodide was added $(50 \mu \mathrm{g} / \mathrm{mL})$ for DNA staining. Cell cycle distribution was analyzed using a FACScan flow cytometer.

\section{Western blot analysis}

Cells lysates were prepared with Pro-Prep lysis buffer (Intron Biotechnology, Seongnam, Korea). The protein samples were separated by SDS PAGE and transferred to polyvinylidene difluoride membranes. After blocking with $5 \%$ bovine serum albumin at room temperature for 1 hour, the membranes were incubated with primary antibodies at $4^{\circ} \mathrm{C}$ overnight, washed, and then incubated with the appropriate secondary antibody for 1 hour at room temperature. The signals were detected using an ECL Kit (Bio-Rad Laboratories, Hercules, CA, USA). The primary antibodies for p21, p27, and Skp2, and horseradish peroxidase-conjugated anti-rabbit and anti-mouse secondary antibodies, were purchased from Santa Cruz Biotechnology (Dallas, TX, USA). Antibodies against cyclin-dependent kinase 2 (CDK2), cyclin-dependent kinase 4 (CDK4), cyclin-dependent kinase 6 (CDK6), cyclin E1, cyclin D1, and tubulin were purchased from Cell Signaling Technology, Inc (Beverly, MA, USA).

\section{Cell transfection}

The Skp2 overexpression plasmid and empty plasmid were purchased from Addgene, Inc. (Cambridge, MA, USA). For transfection experiments, Fugene HD transfection reagent (Promega; Madison, WI, USA) was used following the manufacturer's instructions. Stable cell lines were established after 2 weeks of $\mathrm{G} 418(600 \mu \mathrm{g} / \mathrm{mL})$ selection.

\section{Lentiviral production and infection}

293T cells were transfected with the pLKO.1-sh-mock or pLKO.1-sh-Skp2 plasmid and a lentiviral envelope packaging plasmid (pRSV-Rev, pMD2.G, pMDLg/pRRE) using the jet-PEI transfection reagent (Polyplus, New York, NY, USA) following the manufacturer's protocols. After 24 hours, the virus particles were harvested using a $0.45 \mathrm{~mm}$ syringe filter. HepG2 cells were infected with virus particles for 48 hours in medium containing $8 \mu \mathrm{g} / \mathrm{mL}$ of polybrene (Sigma-Aldrich, St. Louis, MO, USA). The cells were then selected with puromy$\operatorname{cin}(2 \mu \mathrm{g} / \mathrm{mL})$ for 48 hours and used for subsequent experiments.

\section{Statistical analysis}

The data are presented as mean values \pm SD. The differences between two different groups were measured by a Student's $t$-test. A value of $P<0.05$ was considered to be statistically significant.

\section{RESULTS}

\section{Effect of imatinib and GNF-5 on the growth of HepG2 cells}

The chemical structures of imatinib and GNF-5 are shown in Figure 1A. To investigate the effects of imatinib and GNF-5 on the growth of HepG2 cells, we first examined the morphological changes at 24,48 , and 72 hours following treatment with each compound $(20 \mu \mathrm{M})$. The results indicated that imatinib and GNF-5 treatment induced cell death and decreased cell numbers at 48 and 72 hours (Fig. 1B). The results of the cell proliferation assay revealed that both imatinib $(20 \mu \mathrm{M})$ and GNF-5 $(20 \mu \mathrm{M})$ significantly inhibited HepG2 cell growth in a time-dependent manner (Fig. 1C). Additionally, the colony formation assay showed that the number of colonies was markedly decreased following treatment with imatinib $(20 \mu \mathrm{M})$ and GNF-5 $(20 \mu \mathrm{M})$ for 2 weeks (Fig. 1D). Collectively, these results demonstrate that imatinib and GNF-5 significantly inhibited the growth of HepG2 cells.

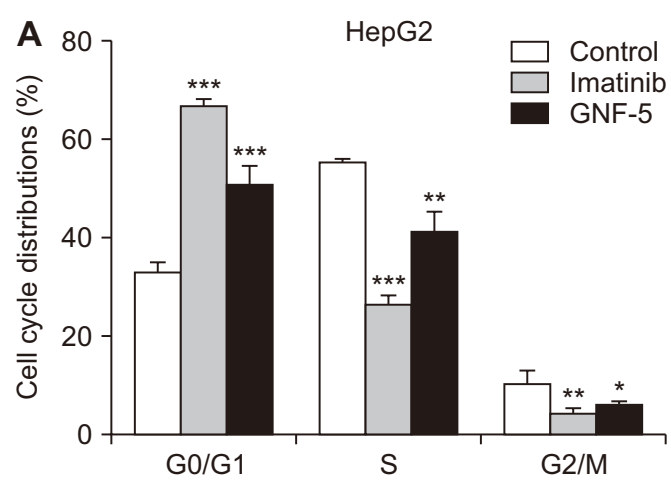

B

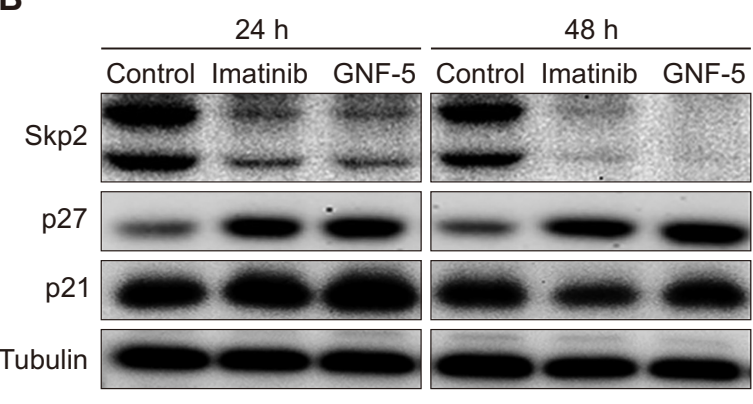

Figure 2. Imatinib and GNF-5 induce cell cycle arrest at the G0/G1 phase in HepG2 cells. (A) Cell cycle distribution of HepG2 cells at 24 hour following treatment with imatinib and GNF-5 as measured by flow cytometry. (B) The effects of imatinib and GNF-5 on the expression of Skp2, p27, and p21 are shown. Skp2, S-phase kinase-associated protein $2 .{ }^{*} P<0.05 ;{ }^{* \star} P<0.01 ;{ }^{* \star *} P<0.001$. 
Imatinib- and GNF-5-induced cell cycle arrest at the G0/G1 phase in HepG2 cells

To further explore the effect of imatinib and GNF-5 on HepG2 cell growth, we determined the cell cycle distribution by flow cytometry after imatinib and GNF-5 treatment. We found that both compounds significantly induced G0/G1 cell cycle arrest in HepG2 cells (Fig. 2A). Western blot analysis revealed that both imatinib and GNF-5 markedly inhibited the expression of Skp2 and increased the expression of the p27 and p21 proteins after 24 and 48 hours of treatment (Fig. 2B). These results suggest that imatinib and GNF-5 induce G0/G1 cell cycle arrest in HepG2 cells by inhibiting Skp2 expression.

\section{Effect of imatinib and GNF-5 on Skp2 overexpressing HepG2 cells}

To assess a functional role for Skp2 in HCC, we established HepG2 cells stably overexpressing Skp2. As shown in Figure 3A, overexpression of Skp2 increased cell proliferation. The cell cycle distribution was not significantly different in Skp2-overexpressing HepG2 cells compared with mock-transfected cells (Fig. 3B). Next, we examined the effect of imatinib and GNF-5 on viability of HepG2 cells. The results indicated that treatment with imatinib and GNF-5 significantly suppressed cell viability of both Skp2-overexpressing and control HepG2 cells (Fig. 3A). As expected, overexpres- sion of Skp2 attenuated the growth inhibitory effect of imatinib and GNF-5 in HepG2 cells (Fig. 3A). In addition, GNF-5 but not imatinib, upregulated the expression of p27 and p21 proteins in Skp2-overexpressing cells. Imatinib and GNF-5 in Skp2-overexpressing cells downregulated the expression of cyclin E1 and cyclin D1 (Fig. 3C).

\section{Effect of imatinib and GNF-5 on viability of Skp2 knockdown HepG2 cells}

To further explore the role of Skp2 protein in proliferation and growth of HepG2 cells, we evaluated the effect of imatinib and GNF-5 on the viability of HepG2 cells following Skp2 knockdown. Knockdown of Skp2 decreased the growth of HepG2 cells at 48 and 72 hours compared with control shmock cells (Fig. 4A). Fluorescence-activated cell sorting analysis revealed that Skp2 knockdown increased the percentage of G0/G1 phase HepG2 cells compared with control sh-mock cells (Fig. 4B). Moreover, treatment with imatinib and GNF5 further inhibited the growth of Skp2 knockdown cells at 48 and 72 hours (Fig. 4A). These results further confirmed that Skp2 plays an important role in HepG2 cell proliferation and cell cycle arrest.
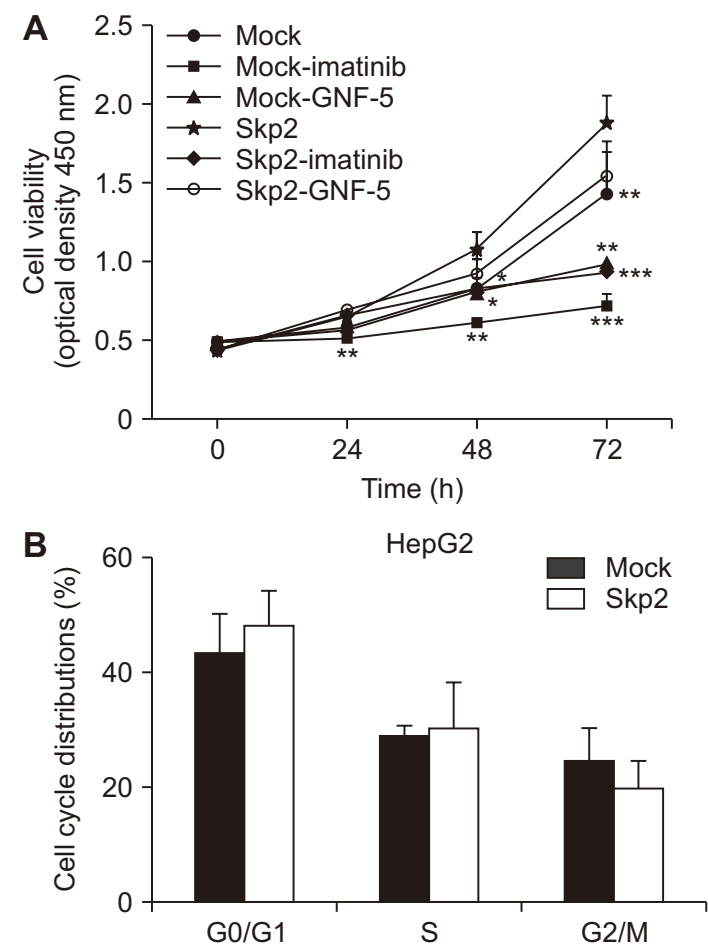

C

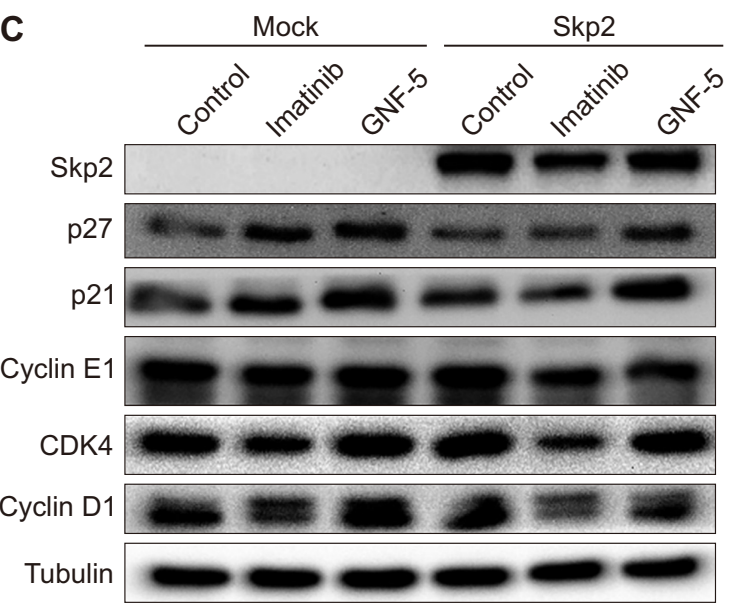

Figure 3. Effect of imatinib and GNF-5 on Skp2 overexpression HepG2 cells. (A) Cell viability was measured after treatment with imatinib or GNF-5 for 0, 24, 48, or 72 hours in HepG2 cells expressing mock or Skp2. (B) Cell cycle distribution was detected in HepG2 cells expressing mock or Skp2 by flow cytometry. (C) Effects of Skp2 overexpression on the levels of Skp2, p21, p27, CDK4, cyclin D1, cyclin E1 and tubulin proteins in HepG2 cells treated with $20 \mu \mathrm{M}$ of imatinib or GNF-5 for 24 hours as measured by Western blot analysis. Skp2, S-phase kinase-associated protein 2; CDK4, cyclin-dependent kinase $4 .{ }^{*} P<0.05 ;{ }^{* \star} P<0.01 ;{ }^{* *} P<0.001$. 

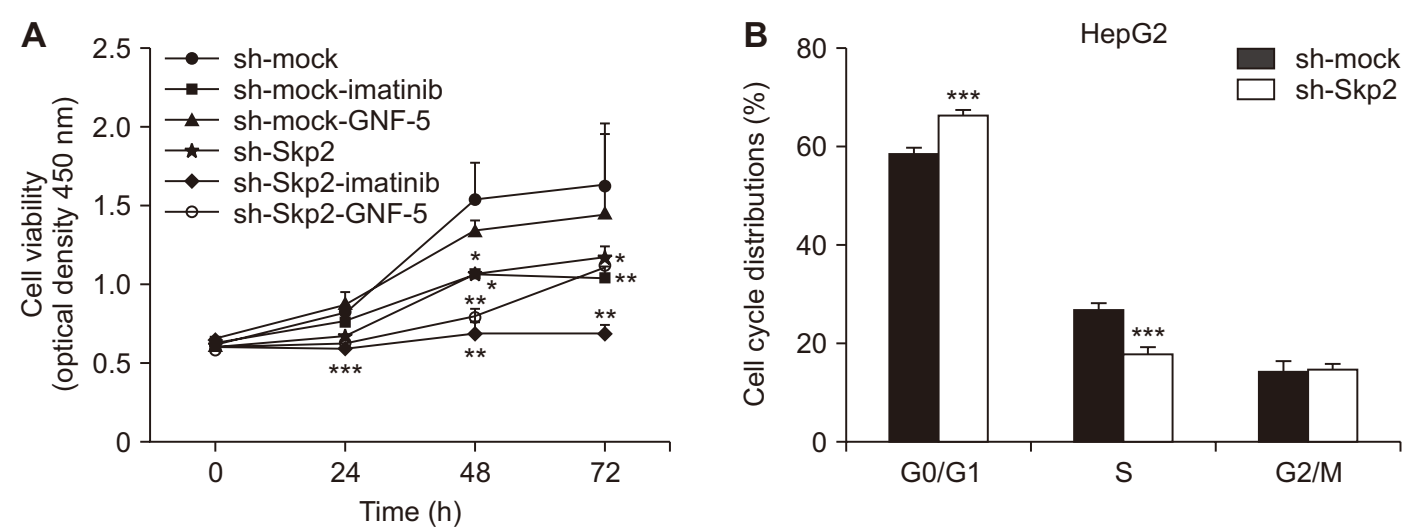

Figure 4. Effect of imatinib and GNF-5 on viability and cell cycle distributions in Skp2 knockdown HepG2 cells. (A) Cell viability was measured after treatment with imatinib or GNF-5 for $0,24,48$, or 72 hours in sh-mock or sh-Skp2 HepG2 cells. (B) Cell cycle distribution was quantitated by flow cytometry in sh-mock or sh-Skp2 HepG2 cells. ${ }^{*} P<0.05$; ${ }^{* *} P<0.01$; ${ }^{* \star} P<0.001$.

\section{DISCUSSION}

Inhibition of the oncogenic kinase activity is considered to be an attractive option for cancer therapy. Imatinib, which is an inhibitor of Bcr-Abl, was developed for CML treatment [12]. GNF-5, originally developed for CML patients carrying imatinib-resistant mutations, can inhibit Bcr-Abl tyrosine kinase activity through selective non-ATP competition [19]. Imatinib has been reported to exhibit potent therapeutic effects in various cancers [20-22]. Our previous study has revealed that imatinib and GNF-5 induce HCC cells apoptosis by inhibiting the expression of Skp2 and p-AKT [15]. In the present study, we evaluated the effect of imatinib and GNF-5 on HCC cell growth and cell cycle regulation. Our results indicated that imatinib and GNF-5 exhibited a time-dependent inhibition of HepG2 cell growth. We found that imatinib and GNF-5 inhibited the growth of HepG2 cells by suppressing the expression of Skp2 and inducing G0/G1 phase arrest. Importantly, Skp2 overexpression restored imatinib- and GNF-5-induced inhibition of cell proliferation, whereas downregulation of Skp2 enhanced imatinib- and GNF-5-mediated antiproliferation. Our results suggest that Skp2 acts as an oncogene to promote the growth of HCC cells.

Skp2 has been reported to regulate p27 and p21 expression and is involved in the G1/S checkpoint transition [23,24]. To determine whether the growth inhibitory effects of imatinib and GNF-5 on HepG2 cells result from dysregulation of the cell cycle, we used flow cytometry to assess cell cycle distribution and immunoblotting to quantify the expression of cell cycle regulatory proteins. We found that imatinib and GNF-5 induced G0/G1 phase arrest by inhibiting Skp2 and upregulating both p27 and p21 levels in HepG2 cells. Cyclin $\mathrm{D}$ and its associated kinases (CDK4 and CDK6) are key components that regulate the $\mathrm{G} 1$ to $\mathrm{S}$-phase transition [21]. The expression of cyclin $\mathrm{E}$ and its associated kinase, CDK2, is increased in late G1/early S-phase when DNA replication is initiated [25]. We also detected the reduced expression of cyclin D1 and cyclin E1 in Skp2 overexpressing HepG2 cells following treatment with imatinib or GNF-5. Moreover, knockdown of Skp2 induced G0/G1 phase arrest in HepG2 cells.

Collectively, our findings revealed that imatinib and GNF5 effectively inhibited HCC cell growth by inhibiting Skp2 and inducing G0/G1 phase cell cycle arrest. Our results indicate that imatinib and GNF-5 have therapeutic potential for HCC treatment.

\section{CONFLICTS OF INTEREST}

No potential conflicts of interest were disclosed.

\section{ORCID}

Haibo Zhang, https://orcid.org/0000-0003-3082-8012 Junkoo Yi, https://orcid.org/0000-0003-2593-6529

Duhak Yoon, https://orcid.org/0000-0002-3983-9757

Zaeyoung Ryoo, https://orcid.org/0000-0001-6993-3624

Inkyu Lee, https://orcid.org/0000-0002-2261-7269

Myoungok Kim, https://orcid.org/0000-0001-6650-7734

\section{REFERENCES}

1. Yang JD, Hainaut P, Gores GJ, Amadou A, Plymoth A, Roberts LR. A global view of hepatocellular carcinoma: trends, risk, prevention and management. Nat Rev Gastroenterol Hepatol 2019;16:589-604.

2. El-Serag HB. Epidemiology of viral hepatitis and hepatocellular carcinoma. Gastroenterology 2012;142:1264-73.e1.

3. Lurje I, Czigany Z, Bednarsch J, Roderburg C, Isfort P, Neumann UP, et al. Treatment strategies for hepatocellular carcinoma - a multidisciplinary approach. Int J Mol Sci 2019;20:1465.

4. Llovet JM, Ricci S, Mazzaferro V, Hilgard P, Gane E, Blanc JF, et al. Sorafenib in advanced hepatocellular carcinoma. N Engl J Med 2008;359:378-90.

5. Carrano AC, Eytan E, Hershko A, Pagano M. SKP2 is required 
for ubiquitin-mediated degradation of the CDK inhibitor p27. Nat Cell Biol 1999;1:193-9.

6. Lee SH, McCormick F. Downregulation of Skp2 and p27/Kip1 synergistically induces apoptosis in T98G glioblastoma cells. J Mol Med 2005;83:296-307.

7. Kanamori A, Matsubara D, Saitoh Y, Fukui Y, Gotoh N, Kaneko $\mathrm{S}$, et al. Mint3 depletion restricts tumor malignancy of pancreatic cancer cells by decreasing SKP2 expression via HIF-1. Oncogene 2020;39:6218-30.

8. Zhou L, Yu X, Li M, Gong G, Liu W, Li T, et al. Cdh1-mediated Skp2 degradation by dioscin reprogrammes aerobic glycolysis and inhibits colorectal cancer cells growth. EBioMedicine 2020;51:102570.

9. Liu Y, Zhou Z, Yan J, Wu X, Xu G. Diosgenin exerts antitumor activity via downregulation of Skp2 in breast cancer cells. Biomed Res Int 2020;2020:8072639.

10. Zhao H, lqbal NJ, Sukrithan V, Nicholas C, Xue Y, Yu C, et al. Targeted inhibition of the E3 ligase $\mathrm{SCF}^{\mathrm{Skp} 2 / \mathrm{cks} 1}$ has antitumor activity in RB1-deficient human and mouse small-cell lung cancer. Cancer Res 2020;80:2355-67.

11. Liu H, Zang L, Zhao J, Wang Z, Li L. Paeoniflorin inhibits cell viability and invasion of liver cancer cells via inhibition of Skp2. Oncol Lett 2020;19:3165-72.

12. Deininger M, Buchdunger E, Druker BJ. The development of imatinib as a therapeutic agent for chronic myeloid leukemia. Blood 2005;105:2640-53.

13. Nazzal M, Sur S, Steele R, Khatun M, Patra T, Phillips N, et al. Establishment of a patient-derived xenograft tumor from hepatitis C-associated liver cancer and evaluation of imatinib treatment efficacy. Hepatology 2020;72:379-88.

14. Bhattacharya S. Fabrication and characterization of chitosanbased polymeric nanoparticles of Imatinib for colorectal cancer targeting application. Int J Biol Macromol 2020;151:104-15.

15. Kim SH, Kim MO, Kim KR. Anti-growth effects of imatinib and GNF5 via regulation of Skp2 in human hepatocellular carcinoma cells. J Cancer Prev 2018;23:170-5.

16. Zhang J, Adrián FJ, Jahnke W, Cowan-Jacob SW, Li AG, lacob $\mathrm{RE}$, et al. Targeting Bcr-Abl by combining allosteric with ATP- binding-site inhibitors. Nature 2010;463:501-6.

17. Liu Y, Shao Z, Liao Y, Xia X, Huang C, He J, et al. Targeting SKP2/Bcr-Abl pathway with Diosmetin suppresses chronic myeloid leukemia proliferation. Eur J Pharmacol 2020;883:173366.

18. Andreu EJ, Lledó E, Poch E, Ivorra C, Albero MP, MartínezCliment JA, et al. BCR-ABL induces the expression of Skp2 through the PI3K pathway to promote p27Kip1 degradation and proliferation of chronic myelogenous leukemia cells. Cancer Res 2005;65:3264-72.

19. Adrián FJ, Ding Q, Sim T, Velentza A, Sloan C, Liu Y, et al. Allosteric inhibitors of Bcr-abl-dependent cell proliferation. Nat Chem Biol 2006;2:95-102.

20. Kotlarz A, Przybyszewska M, Swoboda P, Neska J, Miłoszewska J, Grygorowicz MA, et al. Imatinib inhibits the regrowth of human colon cancer cells after treatment with 5-FU and cooperates with vitamin D analogue PRI-2191 in the downregulation of expression of stemness-related genes in 5-FU refractory cells. J Steroid Biochem Mol Biol 2019;189:48-62.

21. Kim JL, Lee DH, Jeong S, Kim BR, Na YJ, Park SH, et al. Imatinib-induced apoptosis of gastric cancer cells is mediated by endoplasmic reticulum stress. Oncol Rep 2019;41:1616-26.

22. Keshavarz-Pakseresht B, Shandiz SA, Baghbani-Arani F. Imatinib induces up-regulation of NM23, a metastasis suppressor gene, in human Hepatocarcinoma (HepG2) Cell Line. Gastroenterol Hepatol Bed Bench 2017;10:29-33.

23. Barr AR, Cooper S, Heldt FS, Butera F, Stoy H, Mansfeld J, et al. DNA damage during S-phase mediates the proliferationquiescence decision in the subsequent $\mathrm{G} 1$ via $\mathrm{p} 21$ expression. Nat Commun 2017;8:14728.

24. Barr AR, Heldt FS, Zhang T, Bakal C, Novák B. A dynamical framework for the all-or-none G1/S transition. Cell Syst 2016;2:27-37.

25. Koff A, Giordano A, Desai D, Yamashita K, Harper JW, Elledge S, et al. Formation and activation of a cyclin E-cdk2 complex during the G1 phase of the human cell cycle. Science 1992;257:168994. 